\title{
Cytokine-induced airway epithelial ICAM-1 upregulation: quantification by high-resolution scanning and transmission electron microscopy
}

\author{
J. Zhu*, A.V. Rogers*, A. Burke-Gaffney*, P.G. Hellewell ${ }^{+}$, P.K. Jeffery*
}

\begin{abstract}
Cytokine-induced airway epithelial ICAM-1 upregulation: quantification by high-resolution scanning and transmission electron microscopy. J. Zhu, A.V. Rogers, A. BurkeGaffney, P.G. Hellewell, P.K. Jeffery. (C)ERS Journals Ltd 1999.

ABSTRACT: The aim of this study was to investigate the variation of intercellular adhesion molecule (ICAM)-1 which occurs between individual airway epithelial cells of distinct phenotype.

16HBE140 ${ }^{-}(16 \mathrm{HBE})$ and BEAS-2B cell lines and human airway explants were cultured with medium alone or a mixture of tumour necrosis factor (TNF)- $\alpha$ (10 $\left.\mathrm{ng} \cdot \mathrm{mL}^{-1}\right)$ and interferon (IFN)- $\gamma\left(40 \mathrm{ng} \cdot \mathrm{mL}^{-1}\right)$ before being immunogold-labelled and examined quantitatively using sensitive high-resolution electron microscopic techniques.

By enzyme-linked immunosorbent assay there was a 1.6-fold increase of ICAM-1 in the BEAS-2B cells following the cytokine mix which was not apparent in the $16 \mathrm{HBE}$ cells. However, high-resolution scanning electron microscopy demonstrated that an upregulation had occurred; median and ranges for gold particle number per $10 \mu \mathrm{m}^{2}$ cell surface were: $7.9(0-40)$ for nonstimulated and $19.1(0-60$ for stimulated $)(p<0.01$, Mann-Whitney U-test). The value for the nonstimulated BEAS-2B cells was 24.2 (0 60), 3-times higher that the constituitive expression in the $16 \mathrm{HBE}$ cells $(\mathrm{p}<0.01)$, whereas following stimulation, it was $68.5(20-130)(p<0.01)$. Values for explant epithelial outgrowths were similar to the $16 \mathrm{HBE}$ cells. Immunohistochemistry of the explanted mucosa showed both constitutive and upregulated expression of epithelial ICAM-1 associated with basal and indeterminate cells rather than with ciliated or goblet cells.

These results using high-resolution techniques indicate that there is marked cell-tocell variation in cellular adhesion molecule expression and that it is the basal cells and less well differentiated (indeterminate) epithelial cells which are likely to play key roles in leukocyte retention via intercellular adhesion molecule-1.

Eur Respir J 1999; 13: 1318-1328.
\end{abstract}

\begin{abstract}
*Lung Pathology and Applied Pharmacology, National Heart and Lung Institute, Imperial College School of Medicine, London, UK. ${ }^{+}$Section of Medicine, Vascular Biology, Clinical Sciences Centre, Northern General Hospital, Sheffield, UK.
\end{abstract}

Correspondence: P.K. Jeffery

Lung Pathology Unit

Histopathology

Royal Brompton Hospital

Sydney Street

London SW3 6NP

UK

\section{Fax: 441713518435}

Keywords: Adhesion molecules airways

cytokines

electron microscopy

epithelium

Received: August 51998

Accepted after revision January 251999
Intercellular adhesion molecule (ICAM)-1, (CD54) is a $90-\mathrm{kDa}$, inducible surface glycoprotein and one of the major ligands for leukocyte function associated antigen (LFA)-1 and macrophage-1 (Mac-1), members of the $\beta_{2}$ (or CD18) integrin family expressed by leukocytes [1-3]. ICAM-1 is upregulated experimentally by a variety of inflammatory stimuli such as interleukin (IL)-1 and combinations of tumour necrosis factor (TNF)- $\alpha$ and interferon (IFN)- $\gamma$ [4] and its expression in vivo on bronchial epithelial and endothelial cells is considered to be important in respiratory diseases particularly where there is allergic inflammation or viral infection [5-9]. Leukocyte margination, migration, and epithelial accumulation depend upon the upregulated expression of ICAM-1 which facilitates the development of airway inflammation [1012 ] and is also thought to play a role in tumour invasion and metastasis [13].

Whilst ICAM-1 cell surface expression and alteration following stimulation of cultured cells has been determined by enzyme-linked immunoabsorbent assay (ELISA) and flow cytometry $[4,14-17]$, its cell surface localization, cell-to-cell variation and variation between cells of distinct phenotype can best be ascertained and quantified using high-resolution and immunohistological techniques [18]. These data are important as the ELISA technique measures a signal which is as a necessity averaged across the cell cultures and takes no account of the cell-to-cell variation nor the likelihood that cells of distinct phenotype may show large variations in their capacity to express ICAM-1.

In the present study, two well-characterized human bronchial epithelial cell lines were used: $16 \mathrm{HBE} 14 \mathrm{o}^{-}$(16HBE) and BEAS- $2 \mathrm{~B}$ cells, and the results compared with primary cell outgrowths and intact mucosa in which distinct epithelial phenotypes could be identified. Whilst the expression of ICAM-1 on BEAS-2B cells has previously been reported by ELISA, the expression on $16 \mathrm{HBE}$ cells has not. The cells were stimulated in culture with a mixture of TNF$\alpha$ and IFN- $\gamma$ and the cell surface expression of ICAM- 1 in stimulated and nonstimulated cells compared using two 
different methods: ELISA and immunogold labelling assessed by high-resolution scanning electron microscopy (HR-SEM).

For HR-SEM, the presence, distribution and concentration of surface ICAM-1 was demonstrated using an antiICAM-1 monoclonal primary antibody and a secondary goat anti-mouse antibody conjugated to $30 \mathrm{~nm}$ gold (GAM 30). This technique, which allows quantification of the apical cell surface, has previously been reported to be highly sensitive and of value in the assessment of regulated cell surface molecules on single cells [19]. In addition, the intact tissue was examined by light and electron microscopic immunocytochemistry. Cell-to-cell differences in the distribution of ICAM-1 are demonstrated.

\section{Materials and methods}

\section{Cell culture and cytokine stimulation}

The bronchial epithelial cell lines used were: $16 \mathrm{HBE}$ kindly donated by D.C. Gruenert (Cardiovascular Research Institute, University of California, San Francisco, CA, USA) which were originally simian virus (SV) $40 \mathrm{o}^{-}$transformed from a mixed population of differentiated ciliated and nonciliated bronchial epithelial cells (these cells were used at passage 18-28) [20]; and BEAS-2B cells, a cell line derived from human bronchial epithelium after transformation by adenovirus $12-\mathrm{SV} 40$ hybrid virus (kindly provided by C.C. Harris, National Cancer Institute, Bethesda, MD, USA) (these cells were used at passage 34-44) [21]. Glass coverslips $10 \mathrm{~mm}$ in diameter (Chance Proper Ltd, Warley, UK) were coated with a $2 \%$ solution of 3 -aminopropyltriethoxysilane (Sigma Chemical, Poole, Dorset, UK) and placed in 24-well plates. 16HBE and BEAS-2B cells for examination by HR-SEM were seeded at $1.1 \times$ $10^{5}$ cells $\cdot w_{e} l^{-1}$ on the coverslips or into $0.4 \mu \mathrm{m}$ pore size transwells (Coring Costar Corporation, Cambridge, UK) for cells to be examined by transmission electron microscopy (TEM). The cells were also seeded at densities of $1 \times 10^{4}$ cells.well ${ }^{-1}$ onto flat-bottomed Nunclon 96-well microtitre plates for ELISA. All cells were grown under the same conditions as submerged cultures at $37^{\circ} \mathrm{C}$ in $5 \%$ $\mathrm{CO}_{2}$ humidified air in Eagle's minimal essential medium (MEM) supplemented with $10 \%$ foetal bovine serum (FBS), 2\% L-glutamine, 1\% MEM nonessential amino acids, $100 \mathrm{U} \cdot \mathrm{mL}^{-1}$ penicillin and $100 \mathrm{mg} \cdot \mathrm{mL}^{-1}$ streptomycin (Sigma), and the medium changed on alternate days [22]. The cells reached confluence after 4-5 days and were then divided for treatment into two groups: 1) a control, nonstimulated group; and 2) a cytokine stimulated group. The cells of the stimulated group were incubated in culture with media containing the cytokine mix composed of $10 \mathrm{ng} \cdot \mathrm{mL}^{-1} \mathrm{TNF}-\alpha$ and $40 \mathrm{ng} \cdot \mathrm{mL}^{-1}$ IFN- $\gamma$ for a period of $24 \mathrm{~h}$; the concentrations were determined from experiments reported previously [17]. A previously validated explant culture technique was applied for the primary culture of airway epithelial cells [23]. Two $\mathrm{mm}^{2}$ pieces of explanted grossly normal bronchial mucosa from lungs resected for cancer (two nonsmoking females with adeno-carcinoma and two male smokers with squamous carcino-ma, none with a documented history of chronic bronchitis or asthma) were orientated with the epithelial surface uppermost on the above coverslips (three pieces per coverslip), placed in 24-well plates which had previous- ly been rinsed with serum-free medium supplemented with F12/Dulbecco's modified Eagle's medium (DMEM) (GIBCO Laboratories, Paisley, Scotland) including hy-drocortisone $(1 \mathrm{mM})$. Explants were allowed to stick to the coverslips at $37^{\circ} \mathrm{C}$ in $5 \% \mathrm{CO}_{2}$ for $16 \mathrm{~h}$, after which the medium was added gently. Medium was changed at 3-day intervals with hydrocortisone-free supplemented F12/DMEM. The explant cultures of bronchial mucosa were used in two ways: 1) after 5 days of culture, when the outgrowth had just taken, the pieces of mucosa were examined by light microscopy and TEM; and 2) separate pieces of tissue were cultured until their epithelial cell outgrowths reached the edge of each coverslip, usually at 10-14 days, and the relevant monolayer of primary cells was examined by HR-SEM. The explants and primary cell outgrowths were cultured for a further $24 \mathrm{~h}$ in the same medium as that used for the $16 \mathrm{HBE}$ and BEAS-2B cell lines. They were then stimulated with TNF- $\alpha$ and IFN- $\gamma$, as described above.

For immunohistochemistry there was originally tissue from seven patients but only tissue from four patients could be used due to lack of viability and squamoid change in the other three. Therefore, there were four experiments in total. Each experiment consisted of six pieces of tissue taken from a single patient, three pieces to be stimulated and three nonstimulated for baseline. Each experiment was repeated on four occasions so that the final data for the two procedures came from 24 pieces in total, 12 stimulated and 12 nonstimulated.

\section{Enzyme-linked immunosorbent assay}

ICAM-1 expression on 16HBE and BEAS-2B cells was determined using a peroxidase ELISA that had been previously validated $[16,17,24]$. The cells in 96-well plates were incubated for $45 \mathrm{~min}$ with $10 \mu \mathrm{g} \cdot \mathrm{mL}^{-1} \mathrm{RR} 1 / 1$, a mouse anti-human ICAM-1 (CD54) monoclonal antibody (mAb) (a gift from R. Rothlein, Boehringer Ingelheim, Ridgefield, CT, USA), in DMEM medium containing $1 \%$ bovine serum albumin (BSA; GIBCO). The cells in the negative control wells were incubated with DMEM and $10 \mu \mathrm{g} \cdot \mathrm{mL}^{-1}$ mouse myeloma immunoglobulin $(\mathrm{Ig}) \mathrm{G}_{1}$ kappa (MOPC21; a gift of M. Robinson, Celltech, Slough, UK). After washing, a 1:1,000 dilution of a peroxidaselinked goat anti-mouse antibody (TCS, Buckingham, $\mathrm{UK}$ ) in phosphate-buffered saline (PBS) $+10 \%$ goat serum (Sigma) was applied for $45 \mathrm{~min}$ and then incubated for 30 min with $1 \mathrm{mg} \cdot \mathrm{mL}^{-1}$ of the $2,2^{\prime}$-azinobis-(3-ethylbenzthiazoline-6-sulphonic acid) (ABTS; Sigma) substrate in $0.2 \mathrm{M}$ citrate/phosphate buffer, containing $0.1 \% \mathrm{H}_{2} \mathrm{O}_{2}$. The reaction was terminated by the addition of $0.2 \mathrm{M}$ citrate. All incubations were carried out at room temperature. Chromophore development was determined by measuring optical density at $405 \mathrm{~nm}\left(\mathrm{OD}_{405}\right)$ with a Titretec MCC/340 Multiscan microplate reader (Flow laboratories, Rickmansworth, UK). Results are expressed as optical density units (ODU) (mean \pm SEM). Background control values were subtracted from the absorbance readings. Student's t-test was used for comparison of the differences between nonstimulated and stimulated groups $(n=6)$. 


\section{Immunogold-labelling}

Antibodies. RR1/1 and MOPC21 were used at a final concentration of $10 \mu \mathrm{g} \cdot \mathrm{mL}^{-1}$ in $1 \%$ BSA. For HR-SEM and TEM post-imbedding labelling, the secondary layer antibody was goat anti-mouse IgG conjugated to electron microscope grade $30 \mathrm{~nm}$ gold (Amersham Life Scence, Amersham, UK) used at 1:40 and 1:20 dilutions in 1\% BSA, respectively, with $1 \%$ normal goat serum and $10 \%$ normal human serum. For TEM pre-imbedding labeling, the goat anti-mouse IgG conjugated with 15 and 20 nm gold (British Bio Cell, Cardiff, UK) was used at 1:20 dilution.

Cell preparation. The immunogold labelling technique for HR-SEM and TEM pre-imbedding labelling originally reported by DE HARvEN and Soligo [25] was followed. The cells, grown on coverslips or micropore membranes were rinsed twice in $0.01 \mathrm{M}$ PBS and lightly "prefixed" for $10 \mathrm{~min}$ in freshly prepared $0.2 \%$ glutaraldehyde solution with $4 \%$ sucrose buffered in 0.01 M PBS $(\mathrm{pH}$ 7.2). The lightly fixed cell cultures were rinsed extensively with the same buffer supplemented with $0.1 \%$ glycine (Sigma) to quench glutaraldehyde activity, then rinsed again in $1 \%$ BSA. The cells were then incubated with the primary anti-ICAM-1 mAb (RR1/1) for 30 min at room temperature, and negative controls for ICAM-1 were provided by cells incubated with MOPC21 for $30 \mathrm{~min}$. All cells were incubated with immunogold conjugate for $1 \mathrm{~h}$ at room temperature and washed thoroughly in $0.01 \mathrm{M}$ PBS. Post-fixation was in a $2 \%$ glutaraldehyde solution in $0.01 \mathrm{M} \mathrm{PBS}$ at $\mathrm{pH} 7.2$. The cells for HR-SEM were prepared by dehydration in a graded series of $70-100 \%$ absolute ethanol and then critical point dried. A coating of carbon (20-30 nm thick) was applied to conduct charge as required for SEM.

For post-embedding TEM immunogold labelling, the technique of HERRERA [26] was used with modifications to the fixation. The sections were incubated with $1 \%$ BSA in PBS for $5 \mathrm{~min}, 1 \%$ gelatin in PBS for $10 \mathrm{~min}$, and 0.02 $M$ glycine in PBS for $3 \mathrm{~min}$. They were then incubated with RR1/1 or MOPC21 each at a concentration of 100 $\mu \mathrm{g} \cdot \mathrm{mL}^{-1}$ for $2 \mathrm{~h}$ at room temperature.

\section{Observation and quantification of colloidal gold}

Immunogold-labelled coverslips were observed by a high-resolution field emission SEM (S-4000; Hitachi Scientific Instruments Nissei Sangyo Co. Ltd., Tokyo, Japan) fitted with a backscatter detector (K.E. Developments Ltd., Cambridge, UK) which enabled the demonstration of elements of high atomic number (i.e. gold). Backscattered electron images of the cell surface were used for counting gold particles seen against a background of cell surface imaged by secondary electron detectors. The backscatter and secondary electron signals were mixed using a signal mixing device (K.E. Developments Ltd) fitted to the HRSEM. For each experimental group, one observer (J. Zhu) counted five areas from each of three coverslips; the areas were chosen randomly by selection of the four cardinal points of the compass and the centre of each coverslip (fig. 1). In each area, the surfaces of 20 cells were observed and the number of gold colloid particles in five fields over

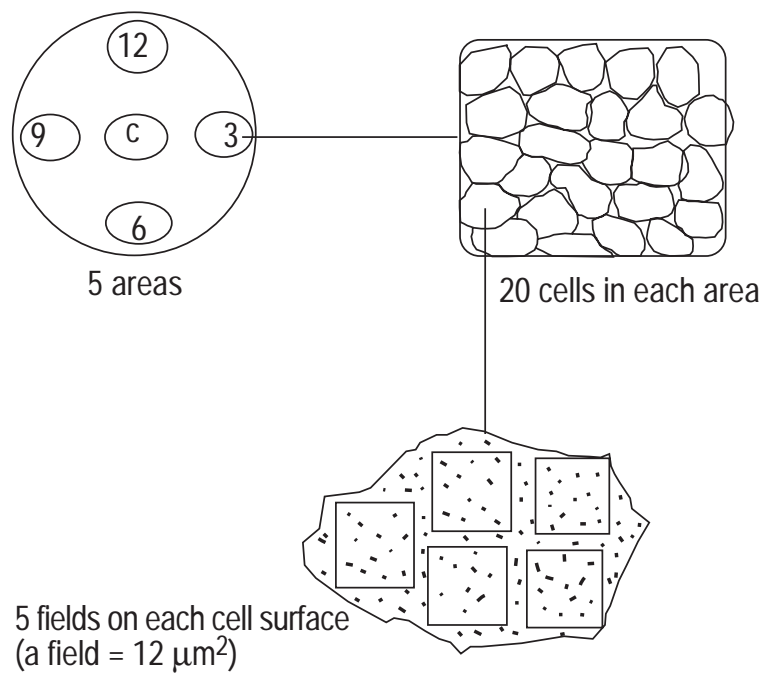

Fig. 1. - For each group, five areas were counted on each of the coverslips at clock positions of $3,6,9$ and 12 and at its centre $(C)$. In each area the surfaces of 20 cells were observed and five fields of each cell surface were counted at $\times 18,000$ magnification. The distribution of gold conjugate on the surface of each cell was expressed as the gold particle number per $10 \mu \mathrm{m}^{2}$ cell surface calculated as the mean of five fields for each cell.

each cell assessed at $\times 18,000$ magnification. Each field was equivalent to $12 \mu \mathrm{m}^{2}$ of cell surface. At this magnification, the $30 \mathrm{~nm}$ gold conjugate was readily observed. The distribution of gold conjugate on the surface of each cell was expressed as the number of gold particles per $10 \mu \mathrm{m}^{2}$ of cell surface, the final value for each cell being calculated from the counts of five fields and expressed as the median value of 300 cells. In order to examine the relationship between the cell surface microvilli frequently present on the $16 \mathrm{HBE}$ cells, the density of cell surface microvilli was also assessed by counting in a similar manner to that used for the immunogold and values were expressed per $12 \mu \mathrm{m}^{2}$ cell surface. The number of immunogold particles associated with each microvillus was also recorded. The relationship between changes in the numbers of microvilli and alterations of gold particles in response to treatment were determined by correlation coefficient (Spearman's rank correlation). Ultrathin sections were observed by TEM (H-7000, Hitachi Scientific Instruments Nissei Sangyo Co. Ltd.) at $\times 30,000$ magnification.

The colloidal gold was used for TEM to demonstrate the ultrastructural localization. The coefficients of variation $(\mathrm{CV})$ for the cell surface distribution and cell-to-cell variation were assessed by HR-SEM and expressed as percentage $\mathrm{CV}$ (i.e. $(\mathrm{sD} /$ mean $) \times 100)$. The error of repeat measurement was also expressed as the percentage CV. As the distribution of the data was markedly skewed, the Mann-Whitney U-test for nonparametric independent data samples was used to compare differences between the experimental groups. A p-value $<0.05$ was taken as statistically significant for all comparisons.

\section{Immunohistochemical staining}

The avidin-biotinylated peroxidase complex (ABC) method was used to demonstrate alterations of ICAM-1 
expression on cells of distinct phenotype in bronchial mucosa in vitro, examined by light microscopy. Three explanted mucosae from each of four patients were removed from the culture dishes, fixed in 4\% paraformaldehyde in PBS for $2 \mathrm{~h}$. The tissues were then transferred to $15 \%$ sucrose/PBS and left at $4^{\circ} \mathrm{C}$ for $24 \mathrm{~h}$. The tissues were embedded in optimal cutting temperature (OCT) compound and snap-frozen. Cryostat sections of $10 \mu \mathrm{m}$ were cut on a Bright's cryostat (Bright Instrument Co. Ltd., Cambridge, UK). The DAKO (High Wycombe, Buckinghamshire, UK) ABC staining procedure for cryostat sections was followed for immunolabelling. The tissues were counterstained with Mayer's haematoxylin and mounted with DPX mountant. Accurate light microscopic identification of ciliated, mucous, basal and indeterminate epithelial cells was made according to their morphological characteristics and position within the epithelium overlying the original explanted tissue. The numbers of each nucleated cell type present and the number of each type immunolabelled in the epithelial layer were counted in a 40 high power $(400 \times)$ microscopic field in all the 12 sections for each experimental group. The means for the data obtained from the 12 sections (i.e. three from each of the four patients) were calculated.

To confirm the bronchial epithelial nature of the cultured cells, outgrowth primary bronchial epithelial cells grown on coverslips, $16 \mathrm{HBE}$ and BEAS-2B cells grown on 8 chamber slides were each labelled with mouse anti-cyto- keratin (CK) 18, CK 17 and CK 10/13 mAbs (Novocastra Laboratories Ltd, Newcastle-upon-Tyne, UK) using the ABC method.

\section{Results}

\section{Epithelial characterization}

The 16HBE cells grew as polarized monolayers with a "cobblestone" appearance (i.e. cells were cuboidal/columnar in shape) and had apical and basolateral membranes defined by the presence of well-developed surface microvilli (figs. $2 b$ and $d$ ) and tight junctions observed by TEM and freeze fracture studies (data not reported). By contrast, the BEAS-2B cells appeared to be a less welldifferentiated cell line as they lacked the "cobblestone" appearance, had a surface with relatively few, thin elongated microvilli (figs. $3 \mathrm{~b}$ and d) and no tight junctions as assessed by TEM. They were also more difficult to culture as a monolayer as they tended to stack one cell upon the other (fig. 4c). The primary cell outgrowths grew as a monolayer of "cobblestone" appearance, had many microvilli (figs. $5 \mathrm{~b}$ and d), had well-formed tight junctions and in this respect their morphology was similar to that of the $16 \mathrm{HBE}$ cell line. In contrast, the explanted mucosa had an intact epithelium which maintained a
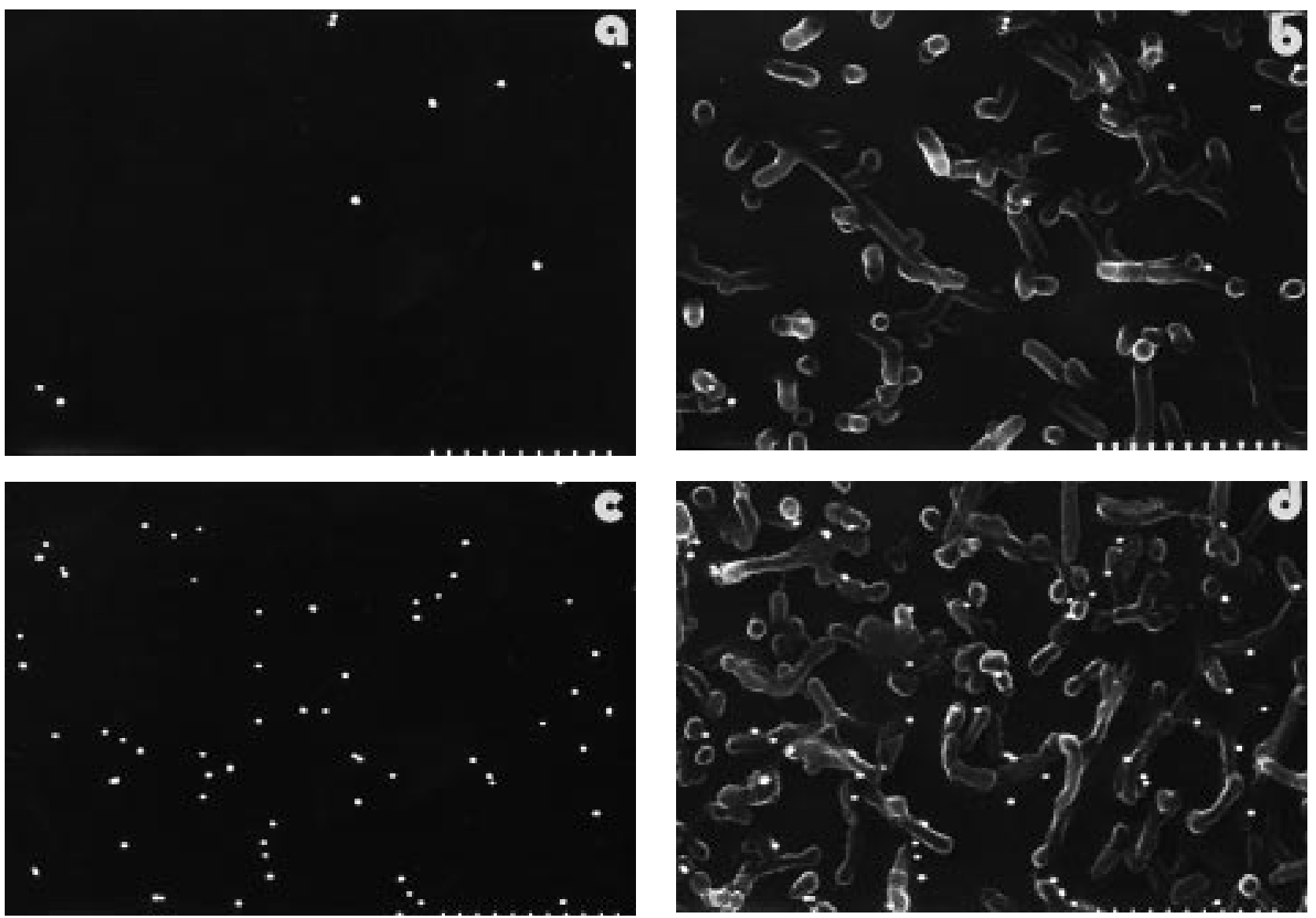

Fig. 2. - High-resolution scanning election microscopy backscatter (a and c) and mixed backscatter and secondary electron (b and d) images of immunogold-labelled 16HBE cells. Intercellular adhesion molecule-1 immunogold is evident on microvilli (b and d). Nonstimulated cells (a and b) have fewer gold particles on their surface than stimulated cells (c and d). (Internal scale bars $=1 \mu \mathrm{m}$.) 

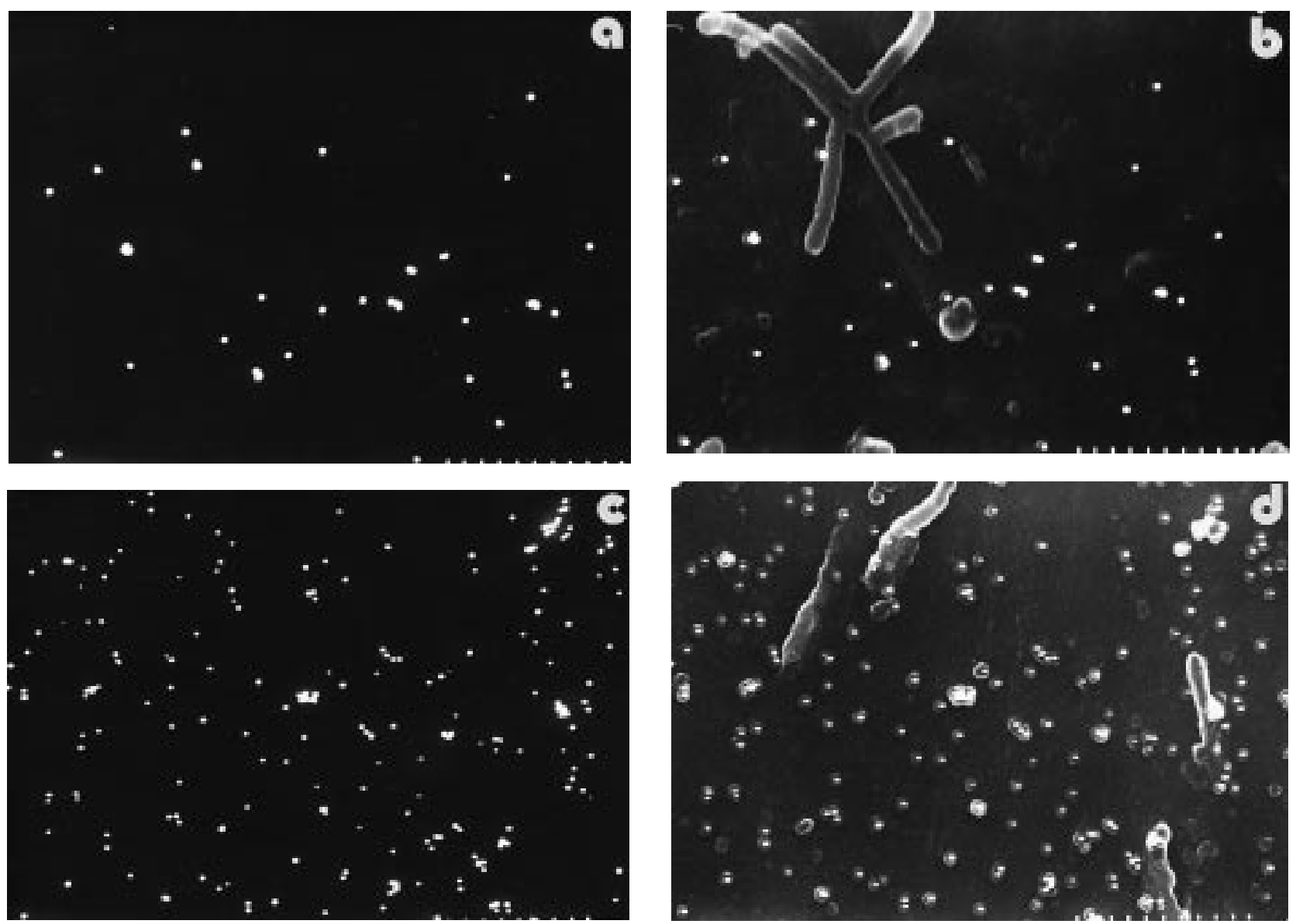

Fig. 3. - High-resolution scanning electron microscopy backscatter (a and c) and secondary electron (b and d) images of immunogold-labelled BEAS2B cells. Stimulated cells ( $\mathrm{c}$ and $\mathrm{d}$ ) had more gold particles on the cell surface than the nonstimulated cells $(\mathrm{a}$ and $\mathrm{b})$. (Internal scale bars $=1 \mu \mathrm{m}$.)

pseudostratified fully differentiated appearance with ciliated, goblet and basal cells (figs. 6a and b).

The primary epithelial cell outgrowth and both cell lines showed $100 \%$ positive immunostaining with the mAb directed against $\mathrm{CK} 18$, which reacts with the most simple cuboidal/columnar epithelia and not with squamous epithelium. Anti-CK 10 and $13 \mathrm{mAb}$, which normally stain cells that are squamous and metaplastic, were negative. Of 5,200 16HBE and 4,400 BEAS-2B cells, 52\% and 83\%, respectively, were immunopositive for $\mathrm{CK} 17 \mathrm{mAb}$, a cytokeratin indicative of an incompletely differentiated cell population reacting mainly with basal cells in the trachea and bronchi. Occasionally $16 \mathrm{HBE}$ cells and cells in the explant outgrowths were periodic acid-Schiff(PAS) or alcian blue $(\mathrm{AB})$ positive, which is evidence for the presence of mucins. BEAS-2B cells were neither PAS nor AB positive.

These results supported the impression, based on morphology, that the $16 \mathrm{HBE}$ cell population at confluence had a tendency to show differentiation and maturation not seen in the BEAS-2B cell line also at confluence.

\section{Enzyme-linked immunosorbent assay results}

Following treatment for $24 \mathrm{~h}$ with the cytokine mix, the ELISA results demonstrated a significant 1.6-fold upregulation of ICAM-1 on the BEAS-2B cells (baseline 1.22 0.02 ODU (mean $\pm \mathrm{SEM}$ ) versus treated $1.98 \pm 0.04, \mathrm{p}<0.01$; $\mathrm{n}=6$; t-test). However, ELISA failed to demonstrate a change in the values for ICAM-1 on the $16 \mathrm{HBE}$ cell line (baseline $0.504 \pm 0.002$ versus treated $0.514 \pm 0.008$, NS). The baseline value for the $16 \mathrm{HBE}$ cell was nearly 3-times lower than that for the BEAS-2B cells.

High resolution scanning microscopy of apical cell surface

The HR-SEM technique demonstrated that anti-ICAM1 immunogold labelling was readily detected on the apical cell surfaces of both cell lines prior to their stimulation (figs. $2 \mathrm{~b}$ and $3 \mathrm{~b}$ ). The error of counting the same area five times was $1.5 \%$ (expressed as $\% \mathrm{CV}$ ). The surface distribution of gold particles on the surface of each cell was relatively homogeneous both at baseline and after stimulation, and the variation across the cell surface was $\sim 1.9 \%$. However, the CV for cell-to-cell variability (i.e. between different cells) was high, particularly on the $16 \mathrm{HBE}$ cells which (by light and transmission microscopy) showed a tendency to phenotypic differentiation; the CVs for baseline on 16HBE and BEAS-2B were 99 and $50 \%$, respectively, before stimulation and 80 and $34 \%$ after stimulation with the cytokine mix. For these results, the median values obtained from counts of 300 cells per group are given. However, for each group, statistical comparison of counts of 100, 200 and 300 cells 

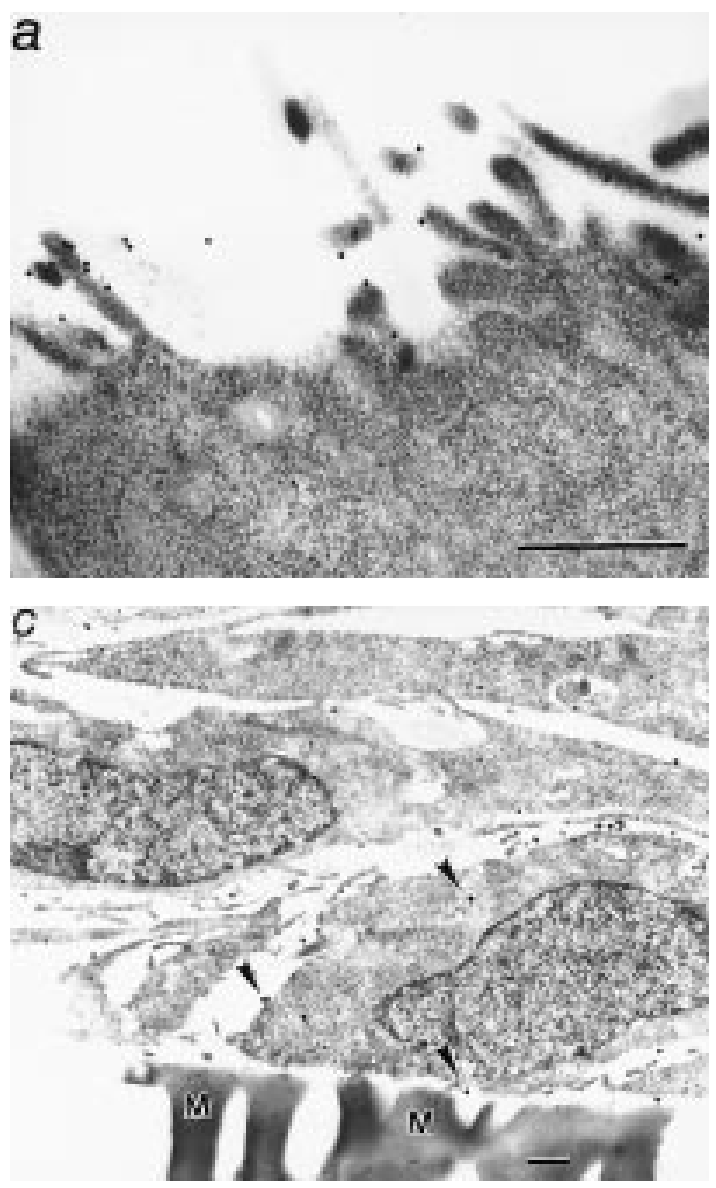

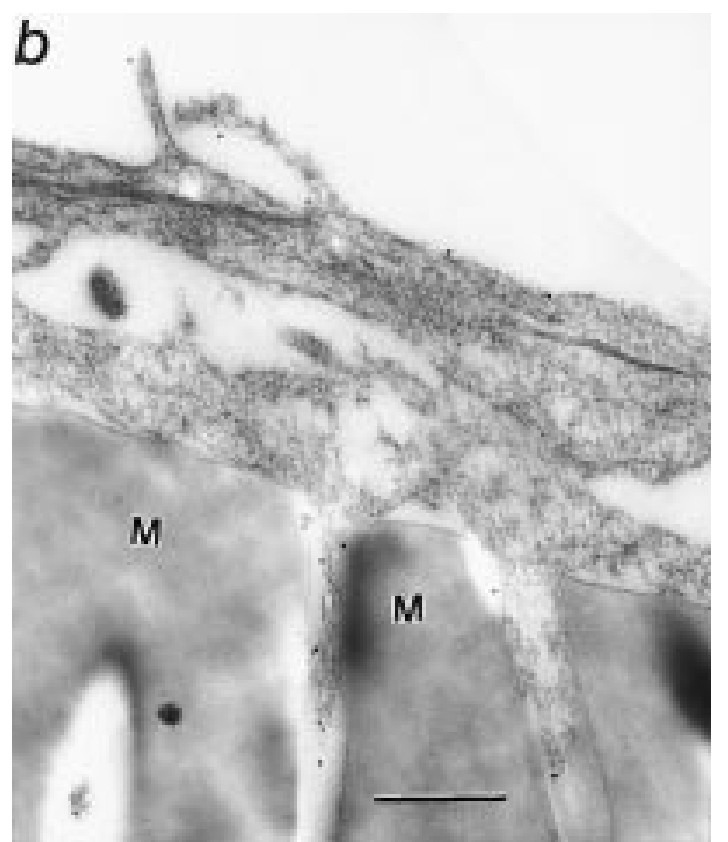

Fig. 4. - Transmission electron microscopy of immunogold-labelled cells after stimulation with the cytokine mix. Gold particles are evident on the luminal surface of $16 \mathrm{HBE}$ cells (a) associated with cell surface microvilli; on the basal aspect of $16 \mathrm{HBE}$ cells (b) on protrusions inserted into the micropores of the culture membrane (M); and on the basolateral surfaces and cytoplasm (arrowheads) of BEAS-2B cells (c) which tended to "stack" one cell upon the other. (a) and (b) are the result of the pre-imbedding labelling technique using 20 and $15 \mathrm{~nm}$ gold, respectively, and (c) is post-imbedding labelling using $30 \mathrm{~nm}$ gold. The diameter of the gold particles used in the last is to enable the labelling to be seen at relatively low magnification. (Internal scale bars $=0.5 \mu \mathrm{m}$.) demonstrated that counts of 100 cells would represent a sufficient sample for an estimate of the median in future studies.

Figure 2 shows the backscatter and mixed backscatter/ secondary electron images of immunogold labelling on nonstimulated (figs. 2a and b) and cytokine-stimulated (figs. 2c and d) $16 \mathrm{HBE}$ cells. Figure 7 shows the results of the quantification presented in the form of a frequency distribution histogram shown together with the median and range. For the nonstimulated $16 \mathrm{HBE}$ cells, only $36 \%$ of the cells had $>10$ particles $10 \mu^{-2}$ (median 7.9, range

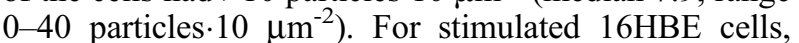
ICAM-1 expression increased markedly when $66 \%$ of the cells had $>10$ particles $\cdot 10 \mu^{-2}$; i.e. $30 \%$ of cells were upregulated with respect to their ICAM-1 expression ( $\mathrm{p}<$ 0.01 , Mann-Whitney U-test). The shape of the frequency distribution curve for the data was unchanged and remained left-skewed.

The constitutive expression of ICAM-1 was significantly higher on BEAS-2B cells than $16 \mathrm{HBE}$ cells $(\mathrm{p}<0.01)$ and, in comparison, $\sim 97 \%$ of BEAS-2B cells had $>10$ particles. $10 \mu^{-2}$ surface (figs. $3 \mathrm{a}$ and $\mathrm{b}$, and 8 ). At baseline, $30 \%$ of the BEAS-2B cells had $>30$ gold particles 10 $\mu^{-2}$ cell surface and only $12 \%$ of the BEAS-2B cells had $>40$ particles $10{\mu \mathrm{m}^{-2}}^{2}$. The baseline median and range for the BEAS-2B cells were 24.2 and $0-60$, respectively (fig. 8 ). Constitutive expression of ICAM-1 on BEAS-2B cells was significantly upregulated after treatment with the cytokine mix such that $98 \%$ of cells had $>30$ particles $\cdot 10$ $\mu \mathrm{m}^{-2}$ and $78 \%$ of the BEAS-2B cells had increased with respect to their ICAM-1 expression, $(p<0.01$ for comparison of stimulated with nonstimulated BEAS-2B cells) (figs. 3c and d, and $8 b$ ). In contrast to the result with stimulated $16 \mathrm{HBE}$ cells, the cytokine stimulated BEAS$2 \mathrm{~B}$ cells showed a change in the shape of the frequency distribution curve for immunogold labelling: i.e. the distribution became symmetrical (fig. 8). By comparison, unstimulated $16 \mathrm{HBE}$ and BEAS-2B cells labelled with MOPC21 (an irrelevant control antibody), had median values of 0.65 and 1.97 , respectively, and no cell had $>5$ particles. $10 \mu^{-2}$, representing the background level of nonspecific labelling.

The primary epithelial cells showed a labelling intensity (fig. 5) and pattern similar to that seen for the $16 \mathrm{HBE}$ cell line but the ranges were larger (fig. 9). Following stimulation, $22 \%$ of the cells were upregulated with respect to their apical surface ICAM-1 expression and there was a significant increase in labelling $(\mathrm{p}<0.01)$. These values and patterns in the primary cells were most closely associated to those of the $16 \mathrm{HBE}$ cell line.

\section{Cell surface microvilli}

Surface microvilli were particularly abundant on the apical surface of the 16HBE cells and relatively infrequent on the BEAS-2B cells, and their association with immunogold labelling for ICAM-1 was investigated. At baseline, the distribution of microvillus number determined in 

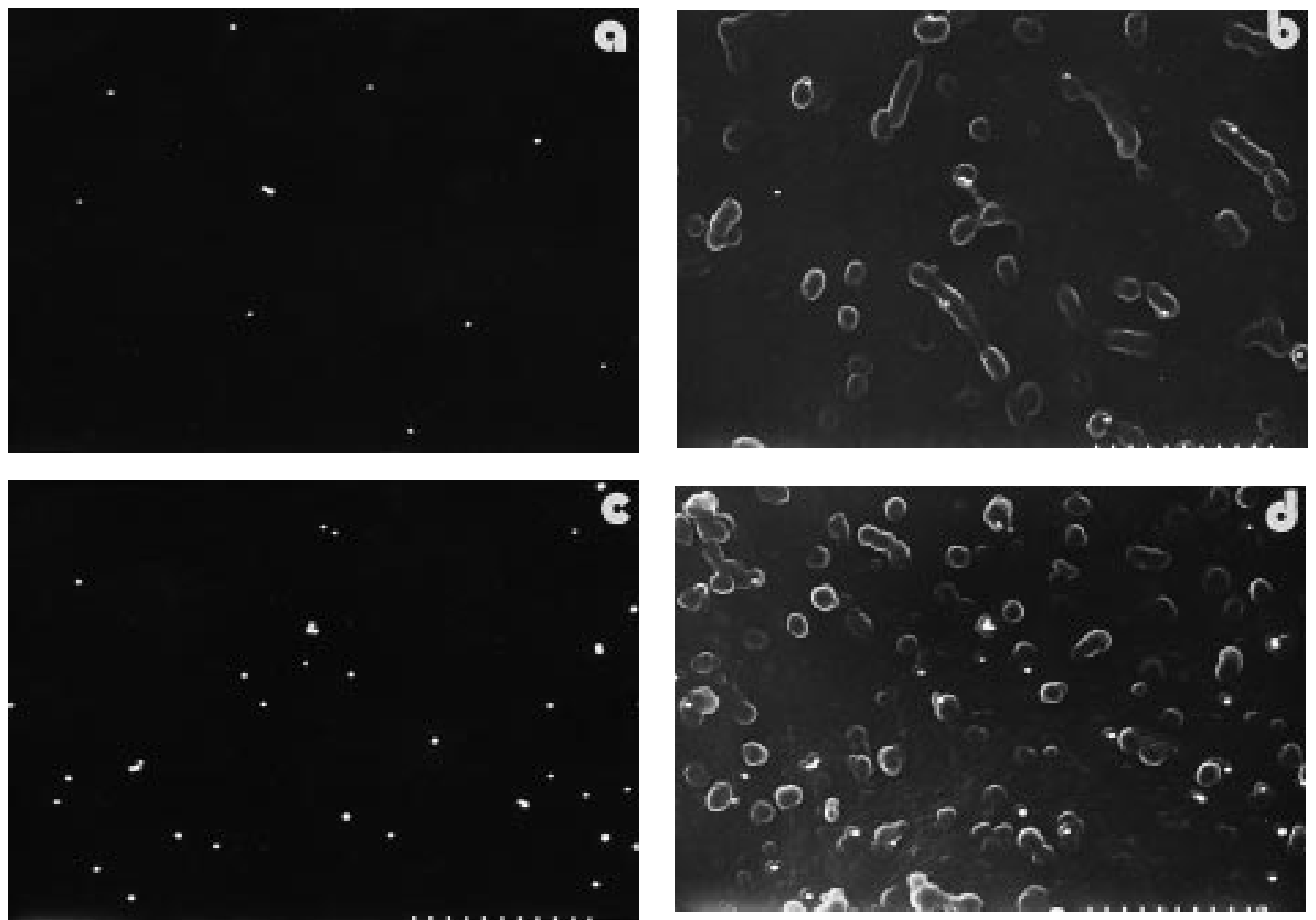

Fig. 5. - High-resolution scanning electron microscopy backscatter (a and c) and secondary electron (b and d) images of primary epithelial cultures showing nonstimulated ( $\mathrm{a}$ and $\mathrm{b}$ ) and a culture stimulated with the cytokine mix (c and $\mathrm{d}$ ). (Internal scale bar $=1 \mu \mathrm{m}$.)

counts of $10016 \mathrm{HBE}$ cells approximated that of a normal distribution with a range of $0-180$ and a median value of 80. There was no relationship between the number of microvilli and ICAM-1 immunolabelling in the nonstimulated cells $(\mathrm{rho}=0.13, \mathrm{p}=0.30)$. Following stimulation by the cytokine mix there was a tendency for a reduction in the number of microvilli (range $0-190 ;$ median $67 ; \mathrm{p}=0.06$, Mann-Whitney U-test compared with the nonstimulated cells). In contrast, the count for immunogold labelled ICAM-1 increased significantly and there was no significant association between the cytokine-induced alteration of microvilli and that of ICAM-1 $(\mathrm{rho}=-0.13, \mathrm{p}>0.20)$.

\section{Transmission electron microscopy of apical and baso- lateral membranes}

Examination by TEM of the $16 \mathrm{HBE}$ and BEAS-2B cell lines and bronchial mucosa showed that labelling for ICAM-1 was associated with the luminal surface of the apical plasma membrane, the lateral cell membrane and the basal aspect of the cells and their basal projections which inserted into the micropore filter (fig. 4). For the $16 \mathrm{HBE}$ cells much of the gold conjugate was attached to the apical microvilli with fewer particles located on the remainder of the cell surface. Immunogold particles were also observed in the cytoplasm (fig. 4). These were most usually observed in the epithelial cells stimulated by TNF- $\alpha / \mathrm{IFN}-\gamma$.
Intercellualr adhesion molecule-1 expression on cells of distinct phenotype

Light microscopy. Immunohistochemical staining of sections of bronchial explants revealed a heterogeneous distribution of ICAM-1 staining. Of the labelled cells, $96.1 \pm$ $3.2 \%($ mean \pm SEM $)$ were basal epithelial cells and $3.9 \pm 0.7 \%$ were indeterminate cells $($ i.e. cells whose phenotype could not be determined with certainty) and no mucous or ciliated cells stained in the nonstimulated samples (fig. 6a). In contrast, following cytokine stimulation $58.4 \pm 4.9 \%$ of the labelled cells were basal and $41.6 \pm 1.3 \%$ were indeterminate cells often with a microvillus border which stained intensely; ciliated and mucous cells remained unstained (fig. 6b). The results of counts of all cells and distinct phenotypes are shown in table 1, expressed as a percentage of the total of the phenotype, respectively. A total of $>3,000$ bronchial epithelial cells were counted for each of the stimulated and nonstimulated groups. At baseline, $\sim 25 \%$ of all epithelial cells expressed ICAM-1, $70 \%$ of basal cells and only $3 \%$ of indeterminate cells stained. TNF$\alpha+$ IFN $-\gamma$ induced a significant increase $(\mathrm{p}<0.01)$ such that $>70 \%$ of epithelial cells expressed ICAM-1, with all basal cells and $97 \%$ of indeterminate cells positive; the shift in proportion was significant statistically $(\mathrm{p}<0.01)$.

Transmission electron microscopy. Quantification of ICAM-1 immunogold labelling was also performed using TEM. Only cells with nuclei included in the cross-section were counted so as to minimize the variation in 

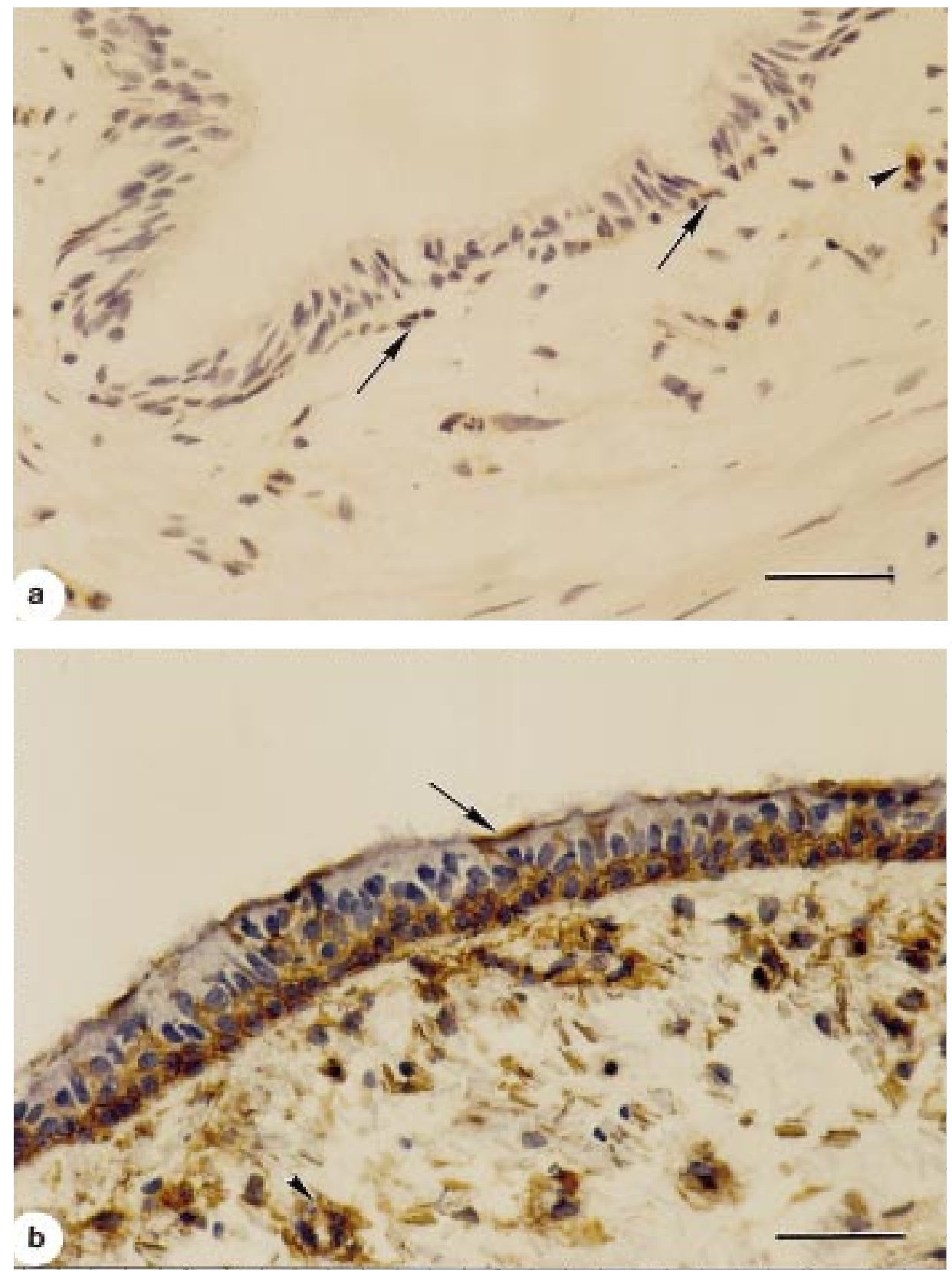

Fig. 6. - Immunohistochemical staining of the bronchial explant in culture to show intercellular adhesion molecule (ICAM)-1 localization. a) The nonstimulated samples showed relatively weak staining of the many basal epithelial cells (arrows), subepithelial fibroblasts and inflammatory cells (arrowheads). b) In the sample stimulated with the cytokine mix there is relatively intense staining for ICAM-1 in all basal cells, and also in indeterminate epithelial cells whose apical microvilli often stain intensely (arrow). Other cells, including endothelial cells (arrowhead) of the subepithelium also now stain for ICAM-1. However, ciliated and globlet cells did not stain. (Internal scale bars $=40 \mu \mathrm{m}$.)

cross-sectional area for each cell. The results are therefore expressed as mean \pm SEM per area cell (table 2). Nonspecific binding was accounted for by subtracting from each value the mean particle number of the background (i.e. the value for the MOPC21 control). At baseline, there were immunogold particles associated with basal and indeterminate cells. After TNF- $\alpha$ and IFN- $\gamma$ stimulation, basal and indeterminate cells showed a 2-fold increase in immunogold particle number per cell $(\mathrm{p}<$ $0.01)$. In no case did fully differentiated ciliated or mucous cells have immunogold particles above that of the background level.

\section{Discussion}

Bronchial epithelial cell lines provide a regular, consistent source of airway epithelium to investigate the factors and mechanisms involved in the regulation of the expression of cell surface adhesion molecules (CAMs) [9, $21,27]$. The most frequently used methods of measurement for CAM expression rely on the detection of fluorescence, ELISA or polymerase chain reaction (PCR) products $[4,16,28]$, none of which allow for the assessment of the variation which exists between individual cells of known morphology nor that which may exist on 


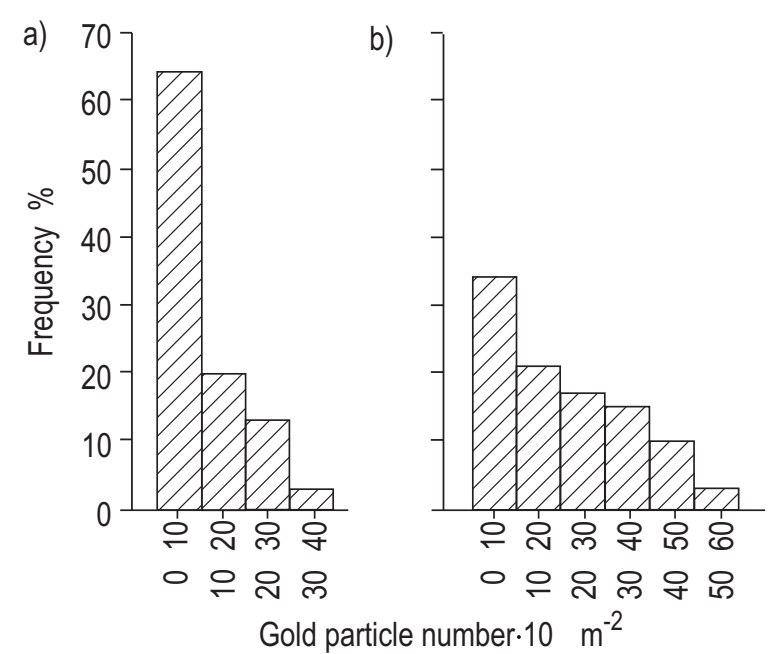

Fig. 7. - Gold particle frequency distribution of nonstimulated (a) and stimulated (b) 16HBE cells assessed by high-resolution scanning electron microscopy. The results are expressed as the number of gold particles per $10 \mu \mathrm{m}^{2}$ area surface against relative frequency. Compared with nonstimulated cells, there was a significant increase in intercellular adhesion molecule-1 expression after stimulation for $24 \mathrm{~h}$ with combined tumour necrosis factor- $\alpha\left(10 \mathrm{ng} \cdot \mathrm{mL}^{-1}\right)$ and interferon- $\gamma$ (40 $\mathrm{ng} \cdot \mathrm{mL}^{-1}$ ) (Mann-Whitney U-test, $\mathrm{p}<0.01 ; \mathrm{n}=300$ ). Median for nonstimulated $=7.9$ and for stimulated $=19.1$ particles $\cdot 10 \mu \mathrm{m}^{-2}$.

each individual cell, due to variations of cell surface projections such as microvilli. Whilst the BEAS-2B cell line has previously been used in studies of ICAM-1 expression [9], it was of interest to analyse the $16 \mathrm{HBE}$ cell line which has not, to the author's knowledge, been studied in this way. The $16 \mathrm{HBE}$ cell line was originally generated by SV40 transformation of a mixed population of differentiated ciliated and nonciliated cells. The cell line grows with a "cobblestone" form and at confluence has a wellformed, relatively abundant cell surface microvilli and well-developed tight junctions [29]. There is evidence, that when the cells are grown on collagen gels with an air/
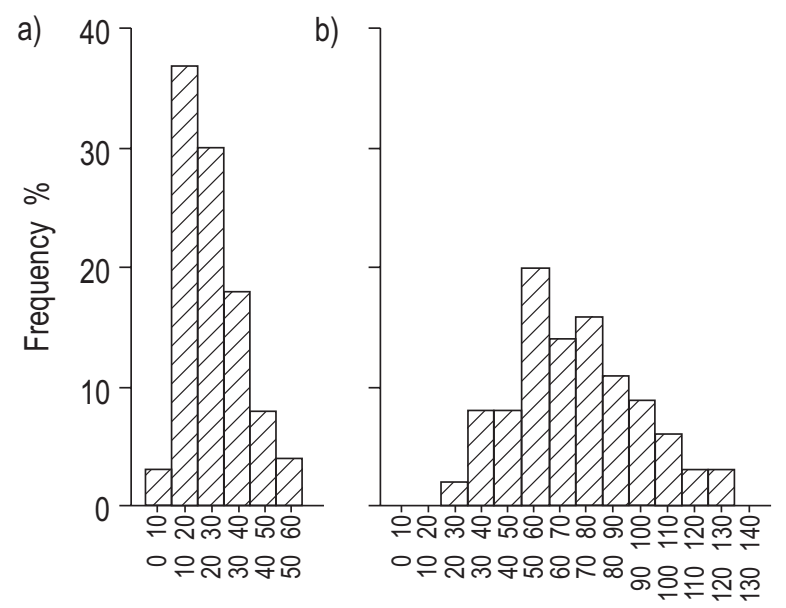

Gold particle number $10 \mathrm{~m}^{-2}$

Fig. 8. - Gold particle frequency distribution of nonstimulated (a) and stimulated (b) BEAS-2B cells as assessed by high-resolution scanning electron microscopy. There was a significant increase in intercellular adhesion molecule-1 after stimulation with a combination of tumour necrosis factor- $\alpha$ and interferon- $\gamma(\mathrm{p}<0.01 ; \mathrm{n}=300)$. Median for nonstimulated $=24.2$ and for stimulated $=68.5$ particles $\cdot 10 \mu \mathrm{m}^{-2}$.
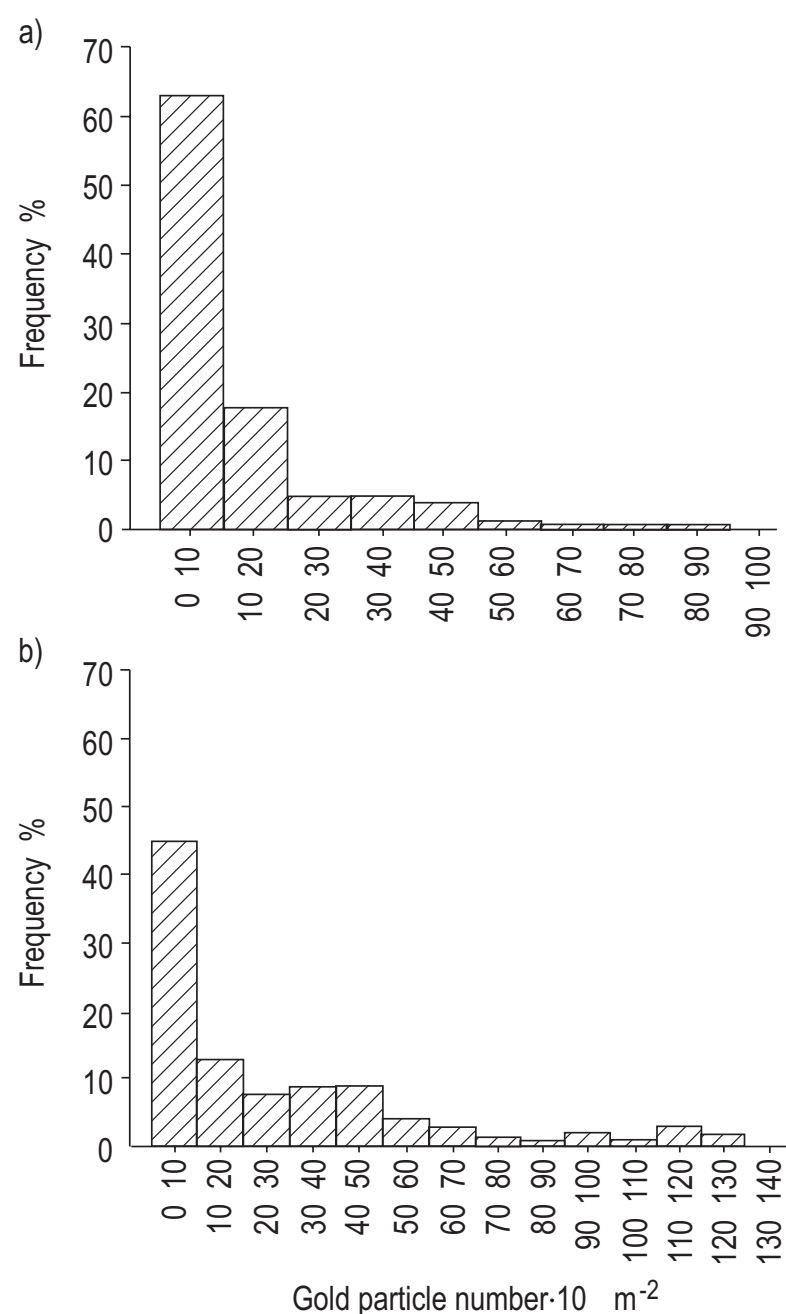

Fig. 9. - Gold particle frequency distribution of nonstimulated (a) and stimulated (b) primary epithelial cells as assessed by high-resolution scanning electron microscopy. There was a significant increase in intercellular adhesion molecule-1 expression after stimulation with the cytokine mix $(\mathrm{p}<0.01 ; \mathrm{n}=300)$. Median for nonstimulated $=7.9$ and for stimulated $=15.4$ particles $\cdot 10 \mu \mathrm{m}^{-2}$.

liquid interface they show features characteristic of their native epithelium, including the presence of cilia and a tendency to show differentiation into distinct cell phenotypes even in submerged culture [20]. By contrast, the BEAS-2B cell line appears to be a less well-differentiated cell line [4] as it lacks the "cobblestone" appearance, has a surface with relatively few, thin elongated microvilli and no tight junctions by TEM and freeze-fracture [29]. The high proportion of $\mathrm{CK} 17$ positivity, resembling that found in basal cells, and the lack of PAS positivity suggests a relatively poorly differentiated cell line. The primary cell outgrowths grew as a monolayer of "cobblestone" appearance, had many microvilli, had well-formed tight junctions and in these morphological respects were similar to the 16HBE cell line at confluence.

The upregulated expression of ICAM-1 plays an important role in both the migration and accumulation of neutrophils, eosinophils and monocytes in inflamed bronchial mucosa and its surface epithelium $[1,2,7,10$, 30]. Using high-resolution SEM and TEM it was found that there are distinct levels of ICAM-1 constitutively 
Table 1. - Immunohistochemistry of explants: cells positive for intercellular adhesion molecule (ICAM)-1

\begin{tabular}{lccccc}
\hline Groups & \% Total cells positive for ICAM-1 & \multicolumn{3}{c}{$\%$ Cells by phenotype positive for ICAM-1 } \\
\cline { 3 - 6 } & & Basal & Indeterminate & Mucous & Ciliated \\
\hline Nonstimulated & $24.5 \pm 1.3(3314)$ & $70.1 \pm 5.2(1312)$ & $3.1 \pm 1.4(988)$ & $0(224)$ & $0(788)$ \\
Stimulated & $71.4 \pm 3.5^{* *}(3324)$ & $100 \pm 0.0^{* *}(1264)$ & $97.2 \pm 6.3^{* *}(952)$ & $0(210)$ & $0(798)$ \\
\hline
\end{tabular}

Results are presented as means \pm SEM with number of cells counted in parentheses. ${ }^{* *}: \mathrm{p}<0.01$, unpaired Student's t-test compared to nonstimulated group $(n=4)$.

expressed on nonstimulated 16HBE and BEAS-2B cells. Whilst the basal level of ICAM-1 expression on 16HBE cells is 3-times lower than that of the BEAS-2B cells, it is of a similar magnitude to that found on the epithelium of explant tissue. It was found that the intensity of ICAM-1 expression could be quantified by counting individual gold particles, and the error of repeatability for such measurements was low $(\mathrm{CV}=1.5 \%)$. Incubation of $16-$ HBE and BEAS-2B cells with the combination of TNF- $\alpha$ and IFN- $\gamma$ resulted in an increased expression of ICAM1. Compared to the control group, there was a 2- or 3fold upregulation of ICAM-1 expression on $16 \mathrm{HBE}$ and BEAS-2B cells, respectively. These results are in agreement with the results of flow cytometry of BEAS-2B cells [4]. However, differences were observed between these two cell lines in the degree of initial ICAM-1 expression in both baseline and stimulated cells. Whilst the upregulation of ICAM-1 following incubation with TNF- $\alpha$ and IFN- $\gamma$ on the BEAS-2B cell line and human bronchial epithelial cells, previously shown using ELISA [9, 16] and flow cytometry [4] was confirmed, a similar magnitude of upregulation on the 16HBE cell line was also found by the high-resolution immunogold method which has not previously been reported and was not apparent when the cells were assessed in parallel by ELISA [24].

These results demonstrate morphological and immunohistochemical changes on the surface of individual cells which has hitherto not been possible. It has been shown that there is a homogeneous distribution of ICAM- 1 on the luminal surface of any single cell and between cells of the BEAS-2B cell line but there was a large cell-to-cell variation in the $16 \mathrm{HBE}$ cell line. Such cell-to-cell variation was not detectable by the ELISA method. Both the ELISA and HR-SEM methods are sensitive techniques, however, the BEAS-2B cells express ICAM-1 with a uniform spatial distribution whose integral signal is compatible with that generated by the ELISA technique. In contrast, it has been shown by application of the HR-SEM technique to the $16 \mathrm{HBE}$ cells that the cell-to-cell distribution is very heterogeneous and that (unlike the BEAS-2B cells) the upregulation only occurs on $30 \%$ of the cells. This is not uniform and contrasts with the pattern of upregulation seen in the BEAS-2B cells. It is likely that the relatively small proportion of upregulated $16 \mathrm{HBE}$ cells does not provide a strong enough signal when integrated over the whole area of the culture when assessed by the ELISA technique. Depending on the method of culture and type of culture medium used, the $16 \mathrm{HBE}$ cell line may express several different phenotypes such as ciliated columnar, secretory (goblet) and basal cells [20], whereas BEAS-2B cells appear to have the characteristics of undifferentiated cells $[4,20]$. These results of high cell-to-cell variation between $16 \mathrm{HBE}$ cells supports the suggestion that differentiation into distinct cell phenotypes may result in different levels of ICAM-1 expression. While on occasions a close spatial association between constitutive ICAM-1 and cell surface microvilli on the $16 \mathrm{HBE}$ cell line has been demonstrated, they are obviously not the determinant for ICAM-1 expression.

In support of this, the relatively less differentiated BEAS-2B cell line with relatively few microvilli had 3times the level of constitutive expression found on the $16 \mathrm{HBE}$ cells. Also the immunohistochemical and TEM analysis of the intact epithelium of the cultured explant bronchial mucosa showed that basal cells had the highest levels of ICAM-1 expression and that the undifferentiated basal and indeterminate cells showed the largest response to cytokine stimulation, whereas the differentiated ciliated and mucus-secreting forms showed the least. It would be instructive to combine this methodology with flow cytometry of disaggregated airway epithelial cells whose phetype may possibly be identified using lectin binding. There may, of course, be explanations other than the state of differentiation, for the differences observed. For example, these may include: the presence or absence of tightjunctions which give rise to a polarized cell, or the extent of contact between cells and their attachment to the basement membrane or culture substrate.

In conclusion, it is suggested that distinct cell phenotypes may have different levels of cell surface adhesion molecule response to cytokines and therefore relatively different roles in the recruitment of inflammatory cells to the airway mucosa. Alterations in the proportions of morphologically distinct airway epithelial cell types (e.g. squamous or mucous cell metaplasia) which occur in airway conditions such as asthma and chronic bronchitis and in response to allergen, irritant or virus may, as a consequence, lead to differing degrees of selection, retention and accumulation of distinct inflammatory cells in the airway surface epithelium.

Table 2. - Immunocytochemistry of explant for intercellular adhesion molecule (ICAM)-1

\begin{tabular}{lcccc}
\hline Groups & Basal cells & Indeterminate cells & Mucous cells & Ciliated cells \\
\hline Nonstimulated & $7.2 \pm 0.2$ & $3.0 \pm 0.41$ & 0 & 0 \\
Stimulated & $15.1 \pm 0.4^{* *}$ & $6.4 \pm 0.27^{* *}$ & 0 & 0 \\
\hline
\end{tabular}

Results are presented as mean \pm SEM of immunogold particles per cell quantified by transmission electron microscopy. ${ }^{* *}: \mathrm{p}<0.01$, unpaired Student's t-test compared to nonstimulated group $(\mathrm{n}=200)$. 
Acknowledgements. The authors thank D. Gruenert and C.C. Harris for providing the cell lines, R. Rothlein for the anti-ICAM-1 antibody, A. Dewar for help in the technical aspects of electron microscopy and L. Oscar for her patience and secretarial expertise.

\section{References}

1. Springer TA. Adhesion receptors of the immune system Nature 1990; 346: 425-433.

2. Albelda SM. Endothelial and epithelial cell adhesion molecules. Am J Respir Cell Mol Biol 1991; 4: 195-203.

3. Kishimoto TK, Larson RS, Corbi AL, Dustin ML, Staunton DE, Springer TA. The leukocyte integrins. $A d v$ Immunol 1989; 46: 149-182.

4. Bloemen PGM, van den Tweel MC, Henricks PAJ, et al. Expression and modulation of adhesion molecules on human bronchial epithelial cells. Am J Respir Cell Mol Biol 1993; 9: 586-593.

5. Tosi MF, Stark JM, Hamedani A, Smith CW, Gruenert DC, Huang YT. Intercellular adhesion molecule-1 (ICAM-1)-dependent and ICAM-1-independent adhesive interactions between polymorphonuclear leukocytes and human airway epithelial cells infected with parainfluenza virus type 2. J Immunol 1992; 149: 3345-3349.

6. Ohkawara Y, Yamauchi $\mathrm{K}$, Maruyama $\mathrm{N}$, et al. In situ expression of the cell adhesion molecules in bronchial tissues from asthmatics with air flow limitation: in vivo evidence of VCAM-VLA-4 interaction in selective eosinophil infiltration. Am J Respir Cell Mol Biol 1995; 12: 4-12.

7. Wegner CD, Gundel RH, Reilly P, Haynes N, Letts LG, Rothlein R. Intercellular adhesion molecule-1 (ICAM-1) in the pathogenesis of asthma. Science 1990; 24: 456459.

8. Chin JE, Winterrowd GE, Hatfield CA, et al. Involvement of intercellular adhesion molecule-1 in the antigeninduced infiltration of eosinophils and lymphocytes into the airways in a murine model of pulmonary inflammation. Am J Respir Cell Mol Biol 1998; 18: 158167.

9. Atsuta J, Sterbinsky SA, Plitt J, Schwiebert LM, Bochner BS, Schleimer RP. Phenotyping and cytokine regulation of the BEAS-2B human bronchial epithelial cell: demonstration of inducible expression of the adhesion molecules VCAM-1 and ICAM-1. Am J Respir Cell Mol Biol 1997; 17: 571-582.

10. Pilewski M, Albelda SM. Adhesion molecules in the lung. Am Rev Respir Dis 1993; 148: S31-S37.

11. Tosi MF, Stark JM, Smith CW, Hamedani A, Gruenert DC, Infeld MD. Induction of ICAM-1 expression on human airway epithelial cells by inflammatory cytokines: effects on neutrophil-epithelial cell adhesion. Am J Respir Cell Mol Biol 1992; 7: 214-221.

12. Springer TA. Traffic signals for lymphocyte recirculation and leukocyte emigration: the multistep paradigm. Cell 1994; 76: 301-314.

13. Mette SA, Pilewski J, Buck CA, Albeda SM. Distribution of integrin cell adhesion receptors on normal bronchial epithelial cells and lung cancer cells in vitro and in vivo. Am J Respir Cell Mol Biol 1993; 8: 562-572.

14. Look DC, Rapp SR, Keller BT, Holtzman MJ. Selective induction of intercellular adhesion molecule-1 by inter- feron-gamma in human airway epithelial cells. $A m J$ Physiol 1992; 92: L79-L87.

15. Krunkosky T, Fischer B, Akley N, Adler K. Tumor necrosis factor alpha (TNF- $\alpha$ )-induced ICAM-1 surface expression in airway epithelial cells in vitro: possible signal transduction mechanisms. Ann N Y Acad Sci 1996; 796: 30-37.

16. Burke-Gaffney A, Hellewell PG. A CD18/ICAM-1 dependent pathway mediates eosinophil adhesion to human bronchial epithelial cells. Am J Respir Cell Mol Biol 1998; 19: 408-418.

17. Burke-Gaffney A, Hellewell PG. Regulation of ICAM-1 by dexamethasone in a human vascular endothelial cell line EAhy926. Am J Physiol 1996; 270: C552-C561.

18. Jeffery PK, Hamid Q, Rogers A, Brain APR, Majumdar $\mathrm{S}$. High resolution scanning and backscatter electron microscopy to determine the number of cell surface antigens, adhesion molecules and mRNA transcripts. J Pathol 1993; 170: 380A.

19. Majumdar S, Wardlaw A, Kay AB, Jeffery PK. High resolution scanning electron microscopy (HRSEM) and light microscopy of cell surface antigens labelled with colloidal gold with or without silver intensification. Eur Respir J 1992; 5: 233S.

20. Cozens AL, Yezzi MJ, Kunzelmann K, et al. CFTR expression and chloride secretion in polarized immortal human bronchial epithelial cells. Am J Respir Cell Mol Biol 1994; 10: 38-47.

21. Reddel RR, Yang K, Gerwin BI, et al. Transformation of human bronchial epithelial cells by infection with SV40 or adenovirus 12-SV40 hybrid virus, or transfection via strontium phosphate coprecipitation with a plasmid containing SV40 early region genes. Cancer Res 1991; 48: 1904-1909.

22. Cozens AL, Yezzi MJ, Chin L, et al. Characterization of immortal cystic fibrosis tracheobronchial gland epithelial cells. Proc Natl Acad Sci USA 1992; 89: 5171-5175.

23. Cromwell O, Hamid Q, Corrigan CJ, et al. Expression and generation of interleukin-8, IL-6 and granulocytemacrophage colony-stimulating factor by bronchial epithelial cells and enhancement by IL-1 beta and tumor necrosis factor-alpha. Immunology 1992; 77: 330-337.

24. Burke-Gaffney A, Hellewell PG. Regional differences in expression and regulation of airway epithelial cell adhesion molecules. Am J Respir Crit Care Med 1995; 151: A192.

25. de Harven E, Soligo D. Scanning electron microscopy of cell surface antigens labeled with colloidal gold. $A m J$ Anat 1986; 175: 277-287.

26. Herrera GA. Ultrastructural postembedding immunogold labeling: applications to diagnostic pathology. Ultrastruct Pathol 1989; 13: 485-499.

27. Pilewski JM, Sott DJ, Wilson JM, Albelda SM. ICAM-1 expression on bronchial epithelium after recombinant adenovirus infection. Am J Respir Cell Mol Biol 1995; 12: $142-148$.

28. Meagher L, Mahiouz D, Sugars K, et al. Measurement of mRNA for E-selectin, VCAM-1 by reverse transcription and polymerase chain reaction. J Immunol Methods 1994; 175: 237-246.

29. Godfrey RWA. Human airway epithelial tight junctions. Micr Res Tech 1997; 38: 488-499.

30. Gundel RH, Wegner CD, Torcellini CA, Letts LG. The role of intercellular adhesion molecule- 1 in chronic airway inflammation. Clin Exp Allergy 1992; 22: 569-575. 